\title{
When Culture Saved The Day: Organization Culture And Crisis Management
}

Fredricka F. Joyner, Indiana University East, USA

David Frantz, Indiana University East, USA

Lynne Maguire, Columbus Regional Hospital, USA

\begin{abstract}
This descriptive case focuses on a health care organization's approach to building an intentional organization culture and how that work contributed to the organization's ability to survive a crisis. Regional Hospital experienced a disaster on a scale few other hospitals have survived - a flood of historic magnitude severely damaged the hospital, forcing it to close its doors for the first time in its 90-year history. In a matter of minutes, the flooding destroyed several critical functions and systems, including the laboratory, pharmacy, information services, food services, and the mechanical and electrical systems. When all was said and done, Regional Hospital incurred more than \$200 million in damages, although this figure was not known for many months. Outside evaluators estimated that it would take 18-24 months for the hospital to reopen, yet Regional Hospital was able to accelerate that timeline, reopening in only five months. Equally significant, during the five-month shut down, Regional Hospital did not lose a single employee or member of its medical staff.
\end{abstract}

Many factors and actions played a role in shaping the hospital's ability to get back on its feet in such an amazing timeframe - not the least of which was the creativity and resourcefulness of the leadership and the employees. Regional Hospital's senior team had well-honed leadership skills built through a decades-long commitment to leadership development. The employee group demonstrated the intrinsic motivation and loyalty associated with a highly engaged workforce. The employee group also displayed a remarkable capacity for flexibility, self-direction, and teamwork.

Keywords: Health Care; Organization Culture; Crisis Management

\section{INTRODUCTION}

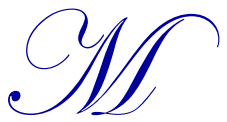

adeline Porter, Chief Strategy Officer for Regional Hospital, had accepted an invitation to make a presentation to MBA students at her alma mater. The students were studying approaches to crisis management and Madeline has been invited to describe what she had learned from her organization's recent experience responding to a flood. Madeline suspected that the students would be expecting information on technical tools and processes but, in reflecting on her experience, what she found more interesting was the important and surprising role that the organization's culture played in successfully responding to the crisis. As she began to shape her presentation, she reflected on her experience.

About a year earlier, Madeline was interrupted by her administrative assistant as she sat with her communications staff in a makeshift meeting room at a parking lot picnic table. "Excuse me Madeline, this gentleman from FEMA (Federal Emergency Management Agency) needs to talk to a senior executive. Can you help him please?" Dressed in a full business suit, tie, with freshly polished black leather shoes, the visitor looked distinctly out of place and uncomfortable outdoors on a hot and humid June afternoon. A devastating flood had 
forced the closure of the hospital a few days prior. Madeline was meeting with her communications team to determine how to handle the influx of national reporters who had been swarming the hospital campus seeking to cover the story. Madeline stood up from the table to greet the FEMA official. "I don't want to trouble you much," he said to Madeline. "All I need is for you to set me up in a conference room with a phone and a computer and I'll be all set." Madeline, temporarily taken aback, thought to herself "where do I even begin?"

What the FEMA official did not realize, but Madeline and her team certainly did, was that there were no conference rooms, no phones, no computers, no infrastructure that worked. No one was even allowed in the crippled facility because it was so unsafe. All 1,800 hospital employees were in limbo, waiting to hear about their jobs and their paychecks. Those who were working to restore order on campus were using outdoor picnic tables and tents along with their personal cell phones as their offices. These were the days just shortly before the widespread use of Twitter and Facebook and the hospital CEO was communicating with employees through local radio stations and the newspaper. The community was waiting to hear when the hospital would reopen, as there was no other hospital or open emergency room in a 30-mile radius. The medical staff was understandably concerned about their patients and their livelihood.

"Come with me; I'm heading to our daily Command Center meeting," said Madeline. We can brief you there on where we are on our key decisions. As Madeline escorted her visitor, she could not help thinking that she was facing a myriad of issues that neither the hospital's disaster planning nor her fancy west coast MBA had really prepared her very well to meet. This was uncharted territory.

\section{BACKGROUND}

A few days before, Regional Hospital experienced a disaster on a scale few other hospitals have survived a flood of historic magnitude severely damaged the hospital, forcing it to close its doors for the first time in its 90 year history. In a matter of minutes, the flooding destroyed several critical functions and systems, including the laboratory, pharmacy, information services, food services, and the mechanical and electrical systems. When all was said and done, Regional Hospital incurred more than \$200 million in damages, although this figure was not known for many months.

Outside evaluators estimated that it would take 18-24 months for the hospital to reopen, yet Regional Hospital was able to accelerate that timeline, reopening in only five months. When the hospital reopened, not only was its facility largely repaired, but key processes and systems had been redesigned, positioning Regional Hospital to be a national leader in health care innovation. Equally significant, during the five-month shut down, Regional Hospital did not lose a single employee or member of its medical staff.

Many factors and actions may have played a role in shaping the hospital's ability to get back on its feet in such an amazing timeframe - not the least of which was the creativity and resourcefulness of the leadership and the employees. Regional Hospital's senior team had well-honed leadership skills built through a decades-long commitment to leadership development. The employee group demonstrated the intrinsic motivation and loyalty associated with a highly engaged workforce. The employee group also demonstrated a remarkable capacity for flexibility, self-direction, and teamwork. How had these competencies developed over time?

\section{Evolving Organizational History and Capabilities}

Regional Hospital was founded in 1917 as a county-owned not-for-profit hospital. Through its first many decades, it was a well-managed community asset that could be characterized as a solid community/county hospital. Regional Hospital was located in a small Midwestern town in a county of approximately 70,000 residents, about a 45-minute drive from a major Midwestern city that was home to several large and well-respected hospital systems. Regional Hospital was known for its comfortable, family-like environment and adequate clinical care. Over 70\% of the "generally content" employee group had never worked for another organization and over $80 \%$ of the physicians had trained at the same university. 
Toward the end of the 1980s, a long-time CEO retired and the Board searched for and recruited a new CEO. The new CEO, Mac Johnson, took a more proactive approach than his predecessor and spent his first few years building a strong senior leadership team. In collaboration with the hospital's Board of Trustees, Johnson focused on developing a strategic plan and vision for the future. Regional's collective management team determined that "good enough" would not work anymore. Changes in reimbursement patterns, patient mix and increasing regional competition led to the realization that there were only two choices - shrink or grow. Johnson and his team chose the latter and began charting a course for the future by clarifying the mission and articulating a set of values that included a commitment to excellence. In subsequent years, an aspirational vision became a companion piece to the mission and values. While revisited and tweaked over the years, the vision remained substantially unchanged and, even today, it serves as the organization's guiding principle - to be the best in the country at everything we do.

Over the years, Regional Hospital became a regional medical center employing approximately 1,800 employees in the hospital, satellite clinics, and various physician medical practices in its service area. There were approximately 250 physicians on staff serving a 10-county area with a population of 300,000. The hospital's services included comprehensive cancer treatment, digestive disorders, cardiac surgery, rehabilitation services, a Lung Institute, and the usual core hospital services. Regional Hospital evolved into the centerpiece of a health network, serving about 10,000 in-patients annually and had about 200,000 out-patient visits. The hospital was the second largest employer in the-county, which was also home to many manufacturing businesses.

The blueprint that Johnson and his team developed and followed to build from that first articulation of mission, values, and vision in the late 1980s (which at the time probably seemed outlandish to some) up to the present included a wide-variety of strategic initiatives. Regional Hospital proactively embraced many of the initiatives that were sweeping the health care industry - facility redesign to accommodate more outpatient services, strategic medical staff recruitment, redesigning the care delivery process itself, and completing a re-branding initiative. However, at the same time, their path departed in an important way from many other similar institutions. Regional Hospital also made a significant investment of time and resource in the development of an intentional culture to support these other initiatives. Madeline and the other members of the senior team came to believe that this investment figured largely in the organization's ability to adapt to and respond to a crisis.

\section{Regional Hospital's Culture Anchors}

In post-mortem discussions after Regional Hospital successfully re-opened, the senior management team spent many hours discussing and identifying the significant variables that they believe allowed for such an amazing response. At the time of the flood, the hospital had an operating surplus which was undeniably a major factor in Regional Hospital's ability to recover. However, the senior team believed that there were other significant initiatives that seemed to prepare the organization's capacity to respond adaptively when all organizational systems disappeared in a matter of hours. There was a general consensus that the intentional development of the organization's culture played a key role in their successful response to the crisis.

Beginning in the 1990s, Regional Hospital initiated the development of an intentional culture that emerged over the next two decades. The culture development work began with a focus on understanding both the needs and expectations of customers. Based on that understanding, an "organizational infrastructure" was developed to guide the work. This infrastructure included the mission, vision, values (Figures 1 and 2) and a dynamic strategy for bringing each element of the model to life. The work to clarify the mission and values and to ultimately articulate an aspirational vision began with the senior team, but it did not end there. It was an iterative, participative process that involved all key stakeholder groups in the socialization and fine-tuning of the ideas included in these frameworks. Once these were finalized, a proactive and ambitious communication strategy was developed and executed to bring them to life for all key stakeholder groups, including employees, patients and their families, the community, and regulators. They became the fundamental underpinning and guidepost for all of the other initiatives that combined to create the intentional culture. 


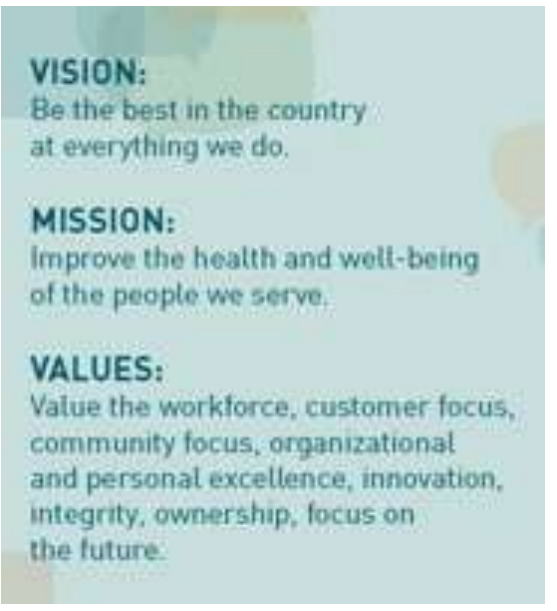

Figure 1: Regional Hospital's Organizational Infrastructure

Strong Leadership - We value strong leadership on the part of each and every member of our team. We believe that shared leadership will result in health and hospital services which are innovative, creative, and highly competitive. Strong, shared leadership will result from informed risk-taking, creativity, and a desire to meet or exceed customer needs through tested innovation.

Teamwork - We recognize that health and hospital care is a collaborative process which we perform in partnership with one another; physicians, nurses, and other direct clinical and diagnostic caregivers assisted by support and administrative staff.

Commitment - We recognize that providing health and hospital services in today's environment requires each and every member of the team to contribute to the best of his or her ability. This frequently requires personal courage, acceptance of responsibility, persistence, and a belief that one's contribution will make a difference.

Citizenship - We believe that we must act collectively as a good corporate citizen. Our work - both individual and organizational - must be performed as good neighbors with community service and responsibility being the underlying values.

Personal Excellence - We value high performance and the continuous pursuit of personal excellence. This value is adopted with the understanding that everything we do can and will be improved. It is in this pursuit of continuous improvement that we will achieve the most efficient, effective, knowledgeable, competent, skilled, and productive work possible.

$\underline{\text { Ethics }}$ - We understand that decisions and action in today's health and hospital environment are increasingly complex and challenging. We are committed to decisions and actions based on honesty, integrity, and sensitivity to personal values.

Caring - We are a hospital and health care organization. We will carry out all of our interactions with one another and our customers, clients, and patients with compassion, care, recognition, and respect. We value family-centered holistic care, positive employee relations, and the ability to balance the needs of the individual with requirements of the organization.

Quality - We believe that quality is the continuous process of meeting or exceeding all our customers' needs and expectations.

Figure 2: Regional Hospital's Value Statements

Building on the mission, vision, and values statements, Regional Hospital clearly articulated attributes of the desired culture, defined as a culture of caring and respect. These attributes, organized around the acronym 
RESPECT (Figure 3) were developed through an in-depth participative process and were, over time, hardwired into many organizational systems, including recruiting and performance review. This work also included the strategic use of stories to shift the cultural conversation and exemplify, or pull forward, aspects of the desired culture.

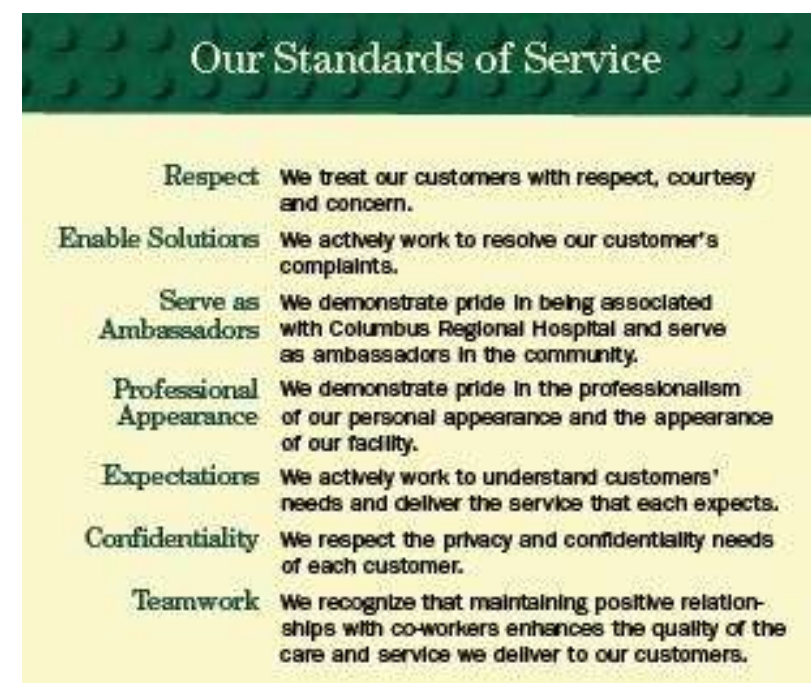

Figure 3: Regional Hospital's Standards of Service

To ensure that the Standards of Service became a way of working and not just "words on a wall," Regional Hospital integrated an active emphasis on employee engagement and teamwork, on specific methodologies and tools that could be used to understand work at a process level and execute improvement efforts, and on measurement. Early on, there was a critical recognition that the only way to achieve competitive levels of customer satisfaction was by working concurrently on improving employee satisfaction. A comprehensive employee engagement strategy was developed that permeated every aspect of the organization.

A measurement system, which included both process and outcome measures and that generated data which could be used to manage performance and to drive improvement, was developed. Regional Hospital was an early adopter, in the health care sector, of the balanced scorecard methodology and, over the years, developed a very sophisticated and institutionalized approach to measurement. One hallmark of this approach was a commitment to transparency of business information and each year comprehensive communication tools and processes were developed to align everyone in the organization around these measures and the work that supported them (Figures 4 and 5).

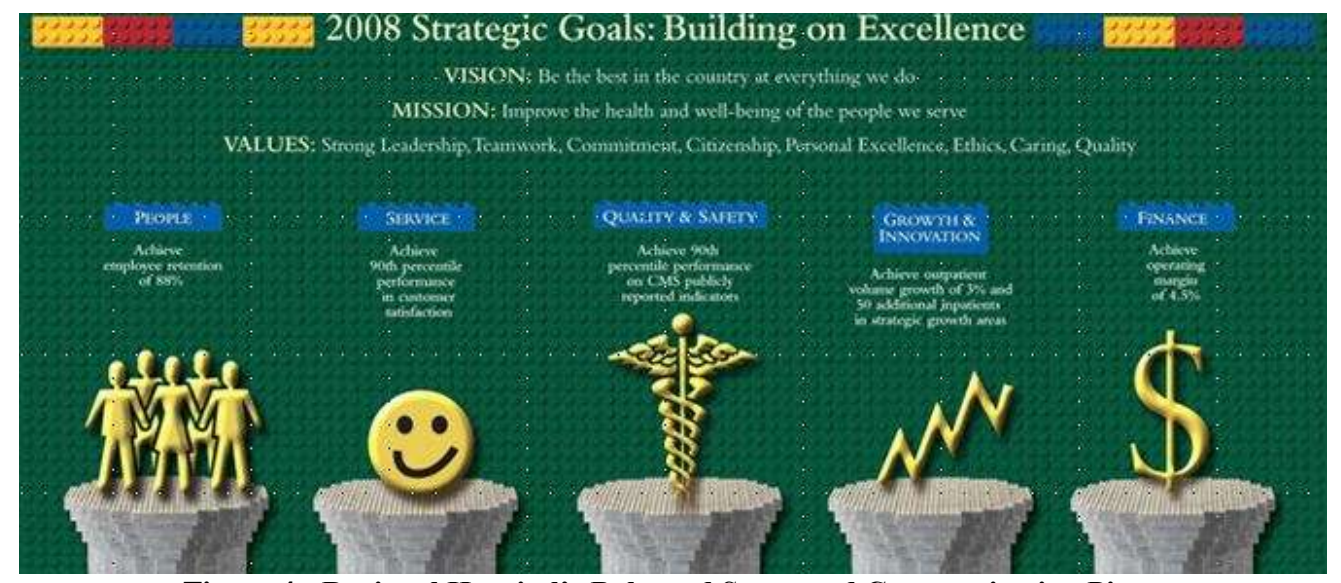

Figure 4: Regional Hospital's Balanced Scorecard Communication Piece 


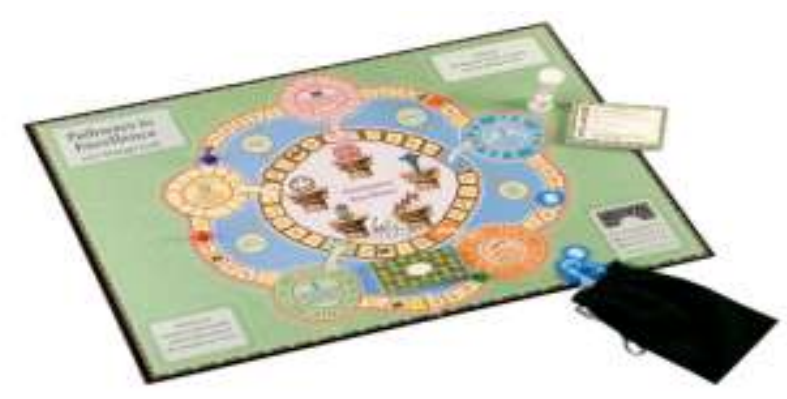

Figure 5: Regional Hospital's Balanced Scorecard Game

These organization development initiatives were focused on multiple organizational levels and included interventions ranging from planning, awareness building, to skill development. They resulted in changes to the planning and measurement processes; the organizational structure; all core human resource systems, including recruitment, performance evaluation, and compensation; stakeholder communication strategies; and the very ways in which individuals were organized to engage in the work and the improvement of the work. The success and results of these initiatives have been recognized by many external sources. For example, Regional Hospital was nationally recognized for its high quality care as the winner of the American Hospital Association's Quest for Quality Prize in 2007 - the highest quality honor awarded by the hospital industry. Regional Hospital is also a Thomson Reuters 100 Top Hospitals, recognized as one of Modern Health care's 100 Best Places to Work in Health care, and is the state's first Magnet-designated hospital for outstanding nursing care.

Taken together, the approaches described above led to the development of a culture that gave the organization a platform which supported achieving the performance levels required to compete for market share and from which to compete for talent. Madeline herself remarked that "the beauty of it is that the strategy is like a secret weapon in that it cannot be easily replicated by competitors. It takes years to build a culture, even when you know what the building blocks are." In further post-mortem discussions, the senior management team acknowledged that, in addition to creating a competitive advantage, these efforts had also contributed to building the organization's capacity for dealing with crisis.

As they worked together in the weeks and months that followed the flood, Regional Hospital employees, physicians, and community volunteers exemplified the hospital's mission, vision, and values. Regional Hospital's CEO was able to talk to employees about showing what a "best in the country recovery" looks like. The crisis afforded hospital employees the unique opportunity to look beyond their roles and work together regardless of titles, skill sets, or expertise. Some of the employees were put to work on helping to restore the facility, some were temporarily deployed to other hospitals in the region, and some were temporarily deployed to not-for-profit agencies in the community that were supporting victims of the flood. No matter the role, the crisis response called for an enormous amount of self-directed decision-making and action. The employees rose to the occasion and were able to work effectively with great autonomy in an environment of heightened ambiguity. This experience brought two decades-worth of work to life for individual employees, the organization, and for the community.

\section{CONCLUSION}

Now, looking back on the whole experience, Madeline realized that she had a newfound appreciation for the importance of organizational culture as a variable. She hoped that Regional Hospital's experience could create some valuable lessons for the future - maybe even find a way to influence what is taught in business schools. Her thoughts returned to the present as she began to think about what lessons she would draw from the experience to share with a group of eager young MBA students at her alma mater.

\section{EPILOGUE}

One unforeseen opportunity that the crisis presented was time to review and improve organizational processes. Work groups had the time to assess their own processes and equipment and to identify opportunities to 
increase efficiencies and service. Meanwhile, those who were temporarily deployed to other hospitals throughout the state during this time came back eager to share the best practices and new approaches to which they had been exposed. This opportunity laid the foundation for Regional Hospital's development of a cutting edge Innovation Center which has become a cultural and operational centerpiece within the organization, region, and industry.

\section{AUTHOR INFORMATION}

Dr. Fredricka F. Joyner has been with Indiana University for the past ten years and is currently an Associate Professor at the Indiana University East School of Business and Economics where she directs the IU East Center for Leadership Development and the Master's in Management program. She has won a number of awards for her teaching and is an active researcher with numerous publications. She is the lead author of Engineering as a Social Activity: Preparing Engineers to Thrive in the Changing World of Work, which was recently published in the American Journal of Engineering Education. She can be reached at fjoyner@iue.edu (Corresponding author)

Dr. David W. Frantz currently serves as the Dean of the School of Business and Economics and Associate Professor of Management at Indiana University East in Richmond, IN. During his tenure as Dean, through the development of on-line programs, the enrollment within the School has doubled since 2007. Dr. Frantz has been teaching online courses since 1998, and has published numerous organizational case studies and articles on organizational change. He can be reached at dfrantz@iue.edu

Lynne Maguire serves as the Chief Strategy Officer for Columbus Regional Hospital (CRH) located in Columbus, Indiana. Innovation has become a central strategy at CRH and her current focus is on guiding the development and work of the Innovation Center that works to create, adapt, and test ideas to deliver smarter health care. She can be reached at lmaguire@crh.org

\section{REFERENCES}

1. Ackoff, R. (1999). Re-Creating the corporation: A design of organizations for the $21^{\text {st }}$ century. New York, New York: Oxford University Press, Inc.

2. Deal, T. \& Kennedy, A. (1982, 2000). Corporate cultures: The rites and rituals of corporate life. New York, New York: Perseus Books Publishing, LLC.

3. Porter, M. (1979). How Competitive Forces Shape Strategy. Harvard Business Review, $57(2) 137$ - 145. 


\section{TEACHING NOTES}

\section{Research Methods}

The names of individuals, the organization, and locations in this case have been disguised to preserve anonymity. The case is based on the authors' experience working in the organization and on information gathered by the authors through individual interviews, conversation with the senior management team, and document review.

\section{Learning Objectives}

Through engaging in this case, students will be able to:

1. articulate the connection between an organization's external environment, strategy and its culture

2. describe the ways in which the intentional development of an organization's culture can become a competitive advantage

3. identify some of the key interventions taken by the organization to develop an intentional culture and the purpose behind each

4. analyze the role that an aspirational vision played in building the organization's capacity to respond to a major organizational crisis

\section{Questions}

1. What were some of the key factors that initially created the need for Regional Hospital to change its culture? (LO \#1)

The organization was getting average performance with its existing culture; as the case states, it was a solid community hospital. The competitive environment was heating up and health care was evolving into a more business-like enterprise. The strategic decision that Johnson and his team faced was "shrink or grow?" The current culture and environment was described in the case in the following manner: Regional Hospital was known for its comfortable, family-like environment and adequate clinical care. Over $70 \%$ of the generally-content employee group had never worked for another organization and over $80 \%$ of the physicians had trained at the same university. This environment would not have delivered growth and it certainly would not have delivered on excellence. Without growth and striving for excellence, the hospital would have been inferior to hospitals in the major city only 45 minutes from Regional Hospital. In all likelihood, the outcome of this dynamic would have been Regional Hospital shrinking to a smaller hospital with less complex services.

Possible follow-up discussion question: What are the challenges of doing new strategic work with the existing staff and culture?

2. What are the elements that make up an organizational culture? How do you define and experience an organizational culture? What differences exist between organizational cultures? (LO \#1)

The focus of this discussion should be on understanding what an organizational culture is, what the dimensions are, and how an organizational culture is formed. The idea of organizational culture first surfaced in the 1960's through the work of Deal and Kennedy $(1982,2000)$ and Russell Ackoff. (1999). It is, in many respects, a concept that had its origin in anthropology. Simply put, the elements of organizational culture are the key symbols, rituals, values, and stories that are widely shared by individuals within organizations. They help to guide behaviors, actions, and beliefs about the organization. Examples of organizations that are well-known for their culture that students might be familiar with are Southwest Airlines, Google, and/or Disney. 
In this case, one might point to the mission statement, the formation of values, training related to process improvements, and the shift to a more collaborative way of planning, along with the vision for the institution.

Possible follow-up activity: Students might be asked to visit two or three websites to identify key cultural elements and reflect on how these might influence actions such as selection and hiring or leadership behaviors. Southwest Airlines, SAS, and Google might be three such cases. Students might also be encouraged to reflect on their own experiences or as a customer of an organization - like a Wal-Mart or a hotel chain.

3. Is the development of an organizational culture a competitive advantage? Or can it be? (LO\#2)

Yes, it may; but first the elements of a competitive advantage must be identified. Michael Porter's work (1979) is the formative model for defining competitive advantage. In short, a competitive advantage is something that sets a firm apart from its competitors. Oftentimes, this is related to specific product features. This is an excellent opportunity to talk about both tangible and intangible elements that might contribute to a firm's competitive advantage. Competitive advantages are competencies or elements that are difficult to imitate and are perceived as valuable by the customer. Human skills, such as customer service orientations or adaptiveness, are sometimes hard to quantify but are extremely important. Imagine a top flight hotel that has every employee oriented toward creating a singularly unique experience for a guest. The service blueprint to make this happen is definitely hard to imitate. It is a combination of extensive orientation and training.

Possible discussion question: Students could be asked to 1) reflect on whether the organizational culture was a competitive advantage and 2) identify specific aspects of the culture that created a competitive advantage.

4. What were several key intervention points that were used to develop an intentional culture and what was the purpose behind each of these? (LO \#3)

Several key intervention points can be identified from the case - the formation of an aspirational vision, the development of a clear set of values, and the implementation of process improvement systems. These were all directed toward fairly broad purposes and include the development of a widely shared understanding of the culture, an emphasis on team work and collaboration, a drive toward excellence, and a general emphasis on employee engagement and involvement. The primary end result may be seen in an increased level of commitment from employees and the ability to respond rapidly to the situation.

5. How would you summarize the organization's vision and how do you see this affecting the employees' response to the crisis situation? (LO \#4)

Summary is "best in the country" performance which means a focus on excellence, innovation, and being proactive. Regional Hospital's CEO was able to talk to employees about showing what a "best in the country recovery" looks like. This was motivational to the employees and moved the majority from being scared and depressed to being energized about what they could do together. The aspirational vision was also key to helping employees see this as an opportunity for growth and renewal.

\section{ADDITIONAL ISSUES}

One of the issues that is not explicitly dealt with in this case is the need for emergency preparedness protocols and procedures. This is not the focus of the case. However, the hospital is required by law and accreditation requirements to have such plans. It is important that students understand this dimension. It also underscores how organizations need to contemplate responses to catastrophic situations. A more recent example is the Japanese tsunami related to nuclear power plants or Hurricane Katrina and the New Orleans experience. Usually catastrophes of this magnitude, even if contemplated, are not fully prepared for, which increases the importance of 
having the right employee orientation to respond optimally. Additionally, there might be further discussions about both crisis management and service recovery plans.

Finally, the importance of having adequate contingency resources cannot be underestimated. In this case, it is unlikely that had the hospital not had adequate operating reserves, they may not have been able to respond as generously to employees. However, part of the reason for adequate reserves may be tied back into the organizational culture designed to focus on both quality and efficiency. In this case, there was an environmental catastrophe. However, in many organizational cases, there may be significant changes based on strategic or competitive shifts. Contingency planning may be just as important, if not more important, in these situations - as well as the intentional development of an organizational culture. 